\section{Zur Milchanalyse.}

Von

\section{H. Schreib.}

In Heft 4 dieser Zeitschrift theilt B. Röse eine Beobachtung mit, die er gelegentlich vergleichender Untersuchungen über Milch bei der Bearbeitung der Seesandmethode erhalten hat.

Darnach hat sich herausgestellt, dass die mit Sand eingetrockneten und zerriebenen Proben, welche in einer Papierhülse aufbewahrt wurden, schon nach wenigen Tagen einen Theil ihres Fettgehaltes einbüssten, so dass die Untersuchung am 2. Tage einen Verlust von 0,27 Proc., am 4. Tage einen solchen von 1,54 Proc. Fett ergab.

Röse ist der Ansicht, dass durch diese auffällige Abnahme, für die er keine Erklärung gefunden hat, häufig Irrthümer entstanden seien, da es in der Praxis vielfach vorkommt, dass die Milchproben gleich nach Eintreffen im Laboratorium eingedampft, aber erst einige Zeit später auf Fettgehalt untersucht werden. Das letztere ist jedenfalls Thatsache; auch ich habe diese Praxis oft anwenden müssen, da ich häufig 20 und mehr polizeilich entnommene Milchproben auf einmal erhielt, während ich höchstens 8 Proben in einem Tage erledigen konnte. Das angebliche Verschwinden des Fettes erschien mir indess völlig räthselhaft, eine auf wissenschaftlichen Gründen beruhende Erklärung ist dafür nicht aufzufinden, auch ist bis jetzt nirgendwo die Beobachtung gemacht, dass Butterfett in trocknem Zustande ohne besondere äussere Einflüsse sich verflüchtigt bez. in Äther unlöslich wird. Es ist ferner auch nicht gut denkbar, dass eine solche Erscheinung, wenn sie regelmässig eintritt, bisher ganz unbeobachtet geblieben sein sollte. Ich habe beispielsweise bei sämmtlichen von mir ausgefübrten Milchanalysen, welche nicht blos behufs oberflächlicher Controle angestellt wurden, die Fettbestimmung doppelt ausgeführt. Hierbei ist es häufig vorgekommen, dass ich die eine Fettbestimmung am 1. Tage, die andere aber erst nach mehr oder weniger längerer Zeit erledigte. Ich hätte in diesem Falle bei der zweiten Bestimmung stets einen Verlust an Fett finden müssen; das ist indess in irgend auffälliger Weise nicht eingetreten. Allerdings bin ich bei der Untersuchung etwas anders verfahren als Röse, indem ich die Milch mit Sand im Hoffmeister'schen Schälchen eindampfte und letztere unzerrieben so lange stehen liess, bis ich die Fettbestimmung vornahm. Auf diese Art war ja insofern ein Unterschied vorhanden gegen das von $R \ddot{o} s e$ angewandte Verfahren, als die Probe eine dichte Masse bildete, also weniger mit Luft in Berührung kam. Es erschien mir jedoch die Röse'sche Beobachtung der Aufklärung bedürftig, und ich habe daher einige Versuche angestellt. Die Milchproben (jedesmal etwa $10 \mathrm{~g}$ ) wurden mit etwa $20 \mathrm{~g}$ gewaschenem und geglühtem Sande im Hoffmeister'schen Schälchen eingedampft, zerrieben und im Tollens'schen Fettextractionsapparat mit Äther ausgezogen; eine Probe wurde sofort untersucht, während die zwei anderen zerrieben und in einer Hülse von Filtrirpapier im Exsiccator aufbewahrt wurden. Ich erhielt:

$$
\begin{aligned}
& \text { am 1. Tage 3,45 Proc. Fett } \\
& \text { - 4. - } 3,57 \\
& \text { - } 5 \text {. - } 3,50
\end{aligned}
$$

Von derselben Milch habe ich ferner zwei Proben unzerrieben im Schälchen stehen lassen, das Zerstossen geschah erst unmittelbar vor der Analyse. Diese ergaben:

$$
\begin{gathered}
\text { am 2. Tage } 3,48 \text { Proc. Fett } \\
-5 . \quad-\quad 3,57-
\end{gathered}
$$

Eine zweite Untersuchungsreihe lieferte folgende Resultate:

$$
\begin{aligned}
& \text { am 1. Tage } 4.25 \text { Proc. Fett } \\
& \text { - } 2 \text {. }-4,35 \\
& \text { - } 1 . \quad-\quad 4,15
\end{aligned}
$$

Die Proben vom 2. und 4. Tage waren am 1. Tage zerrieben und in Papier aufbewahrt. Eine andere Probe, welche am 5. Tage zerrieben und untersucht wurde, ergab 4,21 Proc. Fett.

Ferner nahm ich noch zwei Bestimmungen vor nach einem früher viel angewandten Verfahren, indem ich die Milch in einer Platinschale mit Sandzusatz verdampfte, wobei unter Umrühren alle Körnchen zerdrückt wurden; das Fett wurde mit Benzin ausgezogen, die Schale getrocknet und gewogen und aus der Differenz der Fettgehalt berechnet. Das Ergebniss war:

am 1. Tage 4,00 Proc. Fett

- 4. 403 - .

Aus den mitgetheilten Zahlen geht wohl hervor, dass der von Röse gemachten Beobachtung keine allgemeine Bedeutung beizulegen ist; dieselbe muss ihren Grund in besondern Umständen haben, welche der Aufklärung bedürfen. 